\title{
Altura de planta, diâmetro caulinar e produção do pinhão-manso irrigado sob diferentes níveis de salinidade
}

\author{
Ricardo P. Veras ${ }^{1}$, Eduardo M. 0. Laime ${ }^{2}$, Pedro D. Fernandes ${ }^{3}$, \\ Frederico A. L. Soares ${ }^{2} \&$ Epitácio de A. Freire ${ }^{2}$
}

\begin{abstract}
RESU MO
O pinhão-manso (Jatropha curcas L.) é uma planta oleaginosa, adaptada às condições do semiárido brasileiro, com potencialidades para a produção de biodiesel. Com o objetivo de se avaliar parâmetros de crescimento e produção de pinhão-manso, em lisímetros de drenagem, conduziu-se um experimento em lisímetros de drenagem, em ambiente aberto, entre janeiro/2009 e janeiro/2010, na área experimental da Unidade Acadêmica de Engenharia Agrícola/CTRN/U FCG. Foram estudados os efeitos da salinidade da água de irrigação sobre variáveis de crescimento e de produção do pinhão-manso. Os tratamentos consistiram de cinco níveis de condutividade elétrica da água de irrigação (CEa: 0,6; 1,8; 3,0; 4,2 e 5,4 $\mathrm{dS} \mathrm{m}^{-1}$ ), distribuídos no delineamento experimental em blocos inteiramente casualizados, com quatro repetições, sendo a parcela constituída de uma planta por lisímetro. A coleta de dados se estendeu no período de 210 aos 360 dias após o transplante; ao final do período de estudos, não se verificaram efeitos significativos dos tratamentos sobre altura de plantas e diâmetro caulinar. A produção de sementes foi afetada, significativamente, com coleta de maior quantidade nas plantas irrigadas com água de 2,28 $\mathrm{dS} \mathrm{m}^{-1}$ de condutividade elétrica.
\end{abstract}

Palavras-chave: Jatropha curcas L., irrigação, condutividade elétrica

\section{Plant height, stem diameter and production of jatropha irrigated under different salinity levels}

\begin{abstract}
The jatropha (Jatropha curcas L.) is an oleaginous plant, adapted to the brazilian semiarid conditions, with potentialities to produce biodiesel. Aiming to evaluate its growth and production parameters, an experiment was carried out in drainage lysimeters, between January/2009 and January/2010, in the experimental area of the Academic U nit of Agricultural Engineering of CTRN/UFCG. The effects of the saline irrigation water were studied on the growth and seed yield of jatropha. The treatments consisted of five levels of electrical conductivity of irrigation water (ECw: $0.6 ; 1.8 ; 3.0 ; 4.2$ and $5.4 \mathrm{dS} \mathrm{m}^{-1}$ ), distributed in a completely randomized block design with four replications, being the plot constituted by one plant grown in each lysimeter. The study started on the 210 day up to 360 days after transplanting; at the end of the period, plant height and stem diameter were not significantly affected by salinity of irrigation treatments. On the other hand, the seed production was significantly affected, with the largest quantity produced by plants that received irrigation water with the electrical conductivity of $2.28 \mathrm{dS} \mathrm{m}^{-1}$.
\end{abstract}

Key words: Jatropha curcas L., irrigation, electrical conductivity

Trabalho submetido e selecionado no primeiro Simpósio Brasileiro de Salinidade realizado de 12-15/10/2010 em Fortaleza, Ceará, Brasil ${ }^{1}$ D outorando, CTRN/UFCG. Email: rp-veras@hotmail.com.

2 Pós-Graduandos, UAEA/U FCG Av. Aprígio Veloso 882, CEP 58429-900, Bodocongó, Campina Grande, PB. Email: edu_laime@hotmail.com; fredalsoares@hotmail.com; epitaciodealcantarafreire@hotmail.com

${ }^{3}$ Coordenador de Pesquisa, INSA/MCT Av. Floriano Peixoto, 715, $2^{\circ}$ andar, CEP 58.400-165, Campina Grande, PB. Fone: (83) $2101-6406$. Email: pdantas@insa.gov.br 


\section{INTRODUÇÃO}

O pinhão-manso (Jatropha curcas L) é uma planta pertencente à família Euphorbiaceae, havendo dúvidas sobre sua origem; alguns autores a consideram nativa do Brasil, mas, segundo Toral et al. (2008), seu mais provável local de origem é a América Central.

Com escassez de águas de boa qualidade em todo o mundo, o uso de fontes salinas na irrigação deve ser considerado uma alternativa importante, desde que se garanta o uso de tecnologia para evitar maior impacto às áreas irrigadas, através de um manejo cuidadoso (Vengosh, 2007).

Diante da preocupação atual com o efeito estufa, aquecimento global e com a limitação ao uso das reservas de combustível fóssil, o pinhão-manso, dentre outras oleaginosas, tem despertado interesse dos produtores, do governo e das instituições de pesquisa, por sua rusticidade. Nesse contexto, com a possibilidade do uso do óleo de pinhão-manso para a produção de biodiesel, abrem-se amplas perspectivas para o aumento das áreas de plantio com essa cultura no semiárido nordestino (Drumond et al., 2010).

Outro fator que contribui para tais perspectivas está relacionado à qualidade de muitas fontes hídricas, principalmente as águas de poços, situados no cristalino, e águas superficiais de reservatórios, em locais com propensão à salinização (Medeiros, 1992). Em regiões áridas e semiáridas, a salinização decorre da natureza física e química dos solos, do regime pluvial e da alta evaporação. Naturalmente, o uso de irrigação acarreta a incorporação de sais ao perfil do solo, por conter na água sais solúveis; devido ao seu uso continuado em irrigações, na ausência de lixiviação, o sal se deposita na zona do sistema radicular e na superfície do solo, decorrente da evaporação da água. A salinização do solo progride quando a quantidade de sais, nele acumulada pela água de irrigação, é maior que a quantidade removida pela água de drenagem (Armas et al., 2010).

Pouco se conhece sobre a bioquímica e a fisiologia do pinhão-manso; não existem cultivares definidas e alguns aspectos agronômicos ainda carecem de investigação, como, por exemplo, a população de plantas ideal e a configuração de plantio (Beltrão, 2006); outro aspecto a ser considerado por pesquisadores é a larga distribuição da colheita de sementes, onerando os custos de mão-de-obra. Entretanto, com a possibilidade do uso do óleo do pinhão-manso para a produção do biodiesel, abrem-se novas e amplas perspectivas de estudos, imprescindíveis para se ter tecnologia de suporte ao aumento das áreas de plantio com essa cultura, no semiárido nordestino.

As perspectivas favoráveis ao aumento de área plantada com essa cultura decorrem, não somente dos baixos custos de sua produção agrícola, principalmente na agricultura familiar, com mão-de-obra própria, mas, sobretudo, porque poderá ocupar solos pouco férteis e arenosos; em geral, tais solos são inaptos à agricultura de subsistência, proporcionando, assim, uma nova opção econômica para regiões carentes, principalmente na agricultura familiar (Achten et al., 2008; Toral et al., 2008).

Sem dúvidas, o pinhão-manso deverá se inserir entre as mais promissoras fontes de matéria prima, rica em óleo, para produção de biocombustíveis. As facilidades de seu manejo agrícola, comparativamente a outras espécies, tornam essa espécie bastante atrativa e, especialmente, recomendada para um programa de produção de óleos vegetais.

A literatura disponível, atualmente, sobre a cultura do pinhão-manso ainda é bastante escassa, pois passou a ser objeto de maior interesse nos últimos anos, com as perspectivas de redução do uso do petróleo, decorrente de impacto ambiental, e pela possibilidade de serem usados óleos vegetais como combustíveis. Um dos trabalhos encontrados é o de Nery et al. (2009) que estudaram o crescimento de pinhão-manso, em ambiente protegido, irrigado com níveis de salinidade variando entre 0,6 e 3,0 dS m$~^{-1}$ e verificaram ser a área foliar a variável mais afetada.

Mesmo sendo a espécie Jatropha curcas de baixa exigência hídrica, sobrevivendo em condições de baixa precipitação e adaptada a condições de calor, alta luminosidade e à semiaridez, a garantia de produção será maior com uso de irrigação, precisando ser pesquisada a possibilidade de seu cultivo em condições de salinidade, a exemplo do que foi realizado na germinação e início de crescimento de mudas do próprio pinhãomanso (Andréo-Souza et al., 2010) e com mamoneira e algodoeiro (Cavalcanti et al., 2005; Jácome et al., 2005), outras oleaginosas com potencialidades de cultivo sob estresse salino.

Nesta pesquisa, os estudos consistiram de avaliação de variáveis de crescimento e de produção da cultura do pinhãomanso, irrigado com águas de diferentes níveis de salinidade, em ambiente aberto.

\section{MATERIAL E MÉTODOS}

O experimento foi conduzido em lisímetros de drenagem da Unidade Acadêmica de Engenharia Agrícola, Centro de Tecnologia e Recursos Naturais/UFCG, em Campina Grande, $\mathrm{PB}$, com as coordenadas geográficas $7^{\circ} 15^{\prime} 18^{\prime}$ " de latitude Sul, $35^{\circ} 52^{\prime} 28^{\prime \prime}$ de longitude Oeste e altitude de $550 \mathrm{~m}$. O clima da região, de acordo com a classificação climática de Koppen, adaptada ao Brasil (Pell et al., 2007; Nóbrega, 2010), é mesotérmico semiúmido, com verão quente e seco ( 4 a 5 meses) e chuvas de outono e inverno.

As plantas foram cultivadas em lisímetros, construídos em fibra de vidro, com paredes de $0,75 \mathrm{~cm}$ de espessura e dimensões de 1,60 m de comprimento, 0,90 m de largura e profundidade de $1,0 \mathrm{~m}$. Os lisímetros foram nivelados recebendo, no fundo da caixa, uma camada de brita zero e outra camada de areia lavada, revestidas por uma manta de "Bidim OP-20". Na parte inferior do lisímetro, foi inserido um dreno de PVC, com diâmetro de 25 $\mathrm{mm}$ conectado a um espaço de coleta de todos os lisímetros, através de registros, para avaliação do consumo hídrico das plantas e da evapotranspiração. Sobre a camada de areia, os lisímetros foram preenchidos com material de solo $\left(1,01 \mathrm{~m}^{3}\right)$, retirado em área próxima ao campus da UFCG, onde há ocorrência natural de outra espécie (pinhão-bravo), obedecendo aos perfis originais do local.

As sementes foram fornecidas pelo Instituto Fazenda Tamanduá, no município de Santa Terezinha, Paraíba, coletadas de uma única planta, para se diminuir a variabilidade genética. 
A semeadura foi realizada em tubetes $\left(180 \mathrm{~cm}^{3}\right)$, contendo substrato comercial (palha de arroz calcinada, vermiculita e acículas de pinus trituradas) providenciando-se, previamente, a eliminação das carúnculas para facilitar a germinação. $\mathrm{O}$ transplante para os lisímetros ocorreu 30 dias após germinação, em 12 de janeiro de 2009. As plantas foram irrigadas com água salina, com 5 níveis de salinidade $(\mathrm{N})$, com base na condutividade elétrica da água de irrigação (CEa): $\mathrm{N}_{1}=0,6 ; \mathrm{N}_{2}$ $=1,8 ; \mathrm{N}_{3}=3,00 ; \mathrm{N}_{4}=4,2 \mathrm{e} \mathrm{N}_{5}=5,4 \mathrm{dS} \mathrm{m}^{-1}$. A quantidade de água aplicada em cada irrigação se baseou no balanço hídrico realizado nos lisímetros.

O início da aplicação dos tratamentos ocorreu aos 15 DAT (dias após o transplantio), com turno de rega de três dias. Os dados apresentados neste trabalho foram coletados no período de agosto/2009 a janeiro/2010. O experimento foi distribuído em blocos casualizados, com quatro repetições, sendo a parcela constituída de uma planta por lisímetro.

As irrigações foram manejadas e controladas mediante uso de planilha eletrônica. Na primeira irrigação, um dia após estarem todos os lisímetros em capacidade de campo, aplicaramse $15 \mathrm{~L}$ de água salinizada por planta, de acordo com os tratamentos; nas irrigações posteriores, o volume de irrigação variou em função do balanço hídrico e da fração de lixiviação, estabelecida em 0,20.

Os dados das variáveis de crescimento foram obtidos em avaliação mensais, a partir de 12/08/2009. A altura da planta foi determinada em cm, adotando-se, como critério, a distância entre o colo da planta e a extremidade do broto terminal do ramo principal; o diâmetro caulinar das plantas foi determinado a $5 \mathrm{~cm}$ acima do coleto, utilizando-se de um paquímetro digital. Foi avaliado, também, o número de sementes por planta.

Ao término da fase experimental, os dados coletados foram tabulados e submetidos à análise de variância pelo teste "F" e regressão polinomial (Ferreira, 2000).

\section{RESULTADOS E DISCUSSÃO}

Analisando-se a Tabela 1, em que estão os dados de altura de plantas, em função dos dias após o transplante para os lisímetros, constata-se não ter havido efeito significativo dos níveis salinos sobre essa variável (Tabela 1). A maior taxa de crescimento das plantas, em altura, ocorreu no início, até 210 DAT.
Diferente dos resultados obtidos no presente estudo, Severino et al. (2006), ao submeterem o pinhão-manso a níveis crescentes de salinidade da água de irrigação, em casa de vegetação, na fase inicial de crescimento (30 dias após a emergência), verificaram ter sido afetada a altura das plantas pela condutividade elétrica da água; entre as plantas irrigadas com CEa de 0,6 e 4,2 dS m ${ }^{-1}$, foi constatada redução de 7,85\% por unidade de CEa. Nery et al. (2009) verificaram, também, redução linear na altura das plantas de pinhão-manso, quando

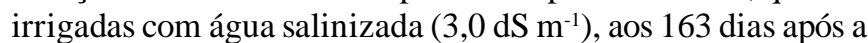
semeadura, com decréscimos de $3,78 \mathrm{~cm}$ por aumento unitário daCEa.

A grande diferença entre as condições desta pesquisa e as realizadas por Severino et al. (2006) e Nery et al. (2009), é que esses autores cultivaram as plantas em ambiente protegido, em recipientes com capacidade de 40 e 200 quilos de material de solo, respectivamente; portanto, cerca de 1/5 do volume dos lisímetros utilizados neste experimento; com maior volume de solo para crescimento do sistema radicular, as plantas cultivadas nos lisímetros são menos afetadas pela salinidade, devendo ser considerado, também, o período de tempo em que estiveram expostas à maior concentração de sais.

$\mathrm{Na}$ literatura são encontradas outras referências à redução na altura de plantas em outras espécies, devido aos efeitos negativos, ocasionados pelo aumento da salinidade (Cavalcanti et al., 2005; Correia et al., 2005; Jácome et al., 2005).

Não se registraram, igualmente, efeitos significativos dos níveis salinos sobre o diâmetro do caule do pinhão-manso, até 360 DAT (Tabela 2). Os valores foram muito aproximados, registrando-se, no nível mais baixo de CEa, aos 210 DAT, diâmetro de 7,67 cm e 8,9 cm, aos 360 DAT. Nery et al. (2009), estudando os efeitos de salinidade em pinhão-manso, observaram redução no diâmetro das plantas, decrescendo 7,35\%, por aumento unitário da CEa; como frisado, anteriormente, o trabalho desses autores foi desenvolvido em ambiente protegido, em recipientes com capacidade de $200 \mathrm{~kg}$ de material de solo, volume cinco vezes menor que o dos lisímetros utilizados nesta pesquisa, o que pode tornar mais drástico o efeito do estresse salino.

Vale et al. (2006) constataram, na fase inicial de crescimento do pinhão-manso (30 dias após a emergência), ter sido afetado, linearmente, o diâmetro caulinar das plantas, pela condutividade elétrica da água, com redução de $7,68 \%$ por aumento unitário

Tabela 1. Resumo da análise de variância da altura de plantas de pinhão-manso, cultivado sob diferentes condições de condutividade elétrica da água de irrigação, em diversas datas após o transplante das mudas para os lisímetros (D AT)

\begin{tabular}{|c|c|c|c|c|c|c|c|}
\hline \multirow{2}{*}{$\begin{array}{l}\text { Fonte de } \\
\text { variação }\end{array}$} & \multirow{2}{*}{ GL } & \multicolumn{6}{|c|}{ Quadrados médios } \\
\hline & & 210DAT & 240DAT & 270DAT & 300DAT & 330DAT & 360DAT \\
\hline Salinidade & 4 & $41,17 \mathrm{~ns}$ & $148,37 n s$ & 326,80 ns & $276,17 n s$ & $282,07 n s$ & $260,32 \mathrm{~ns}$ \\
\hline Bloco & 3 & $45,60 \mathrm{~ns}$ & 17,38ns & $59,38 \mathrm{~ns}$ & $54,18 \mathrm{~ns}$ & $88,98 \mathrm{~ns}$ & $101,78 \mathrm{~ns}$ \\
\hline Resíduo & 12 & 85,30 & 105,17 & 108,30 & 108,14 & 78,27 & 89,49 \\
\hline $\mathrm{CV}(\%)$ & & 6,56 & 7,04 & 6,92 & 6,79 & 5,68 & 5,99 \\
\hline Salinidade $\left(\mathrm{dS} \mathrm{m}^{-1}\right)$ & & \multicolumn{6}{|c|}{ Média $(\mathrm{cm})$} \\
\hline 0,6 & & 142,75 & 148,25 & 149,50 & 152,50 & 154,25 & 156,00 \\
\hline 1,8 & & 142,75 & 150,00 & 152,00 & 154,50 & 155,50 & 156,75 \\
\hline 3,0 & & 139,00 & 139,75 & 145,00 & 146,25 & 150,50 & 153,50 \\
\hline 4,2 & & 136,00 & 138,75 & 141,00 & 145,75 & 148,25 & 151,25 \\
\hline 5,4 & & 143,50 & 152,00 & 164,75 & 166,25 & 169,75 & 171,75 \\
\hline
\end{tabular}

** significativo a $1 \%$ de probabilidade; $\mathrm{ns}=$ não significativo pelo teste $\mathrm{F}$ 
Tabela 2. Resumo da análise de variância do diâmetro caulinar de plantas de pinhão-manso cultivado sob diferentes condutividades elétricas da água de irrigação, em várias datas do ciclo

\begin{tabular}{|c|c|c|c|c|c|c|c|}
\hline \multirow{2}{*}{$\begin{array}{l}\text { Fonte de } \\
\text { variação }\end{array}$} & \multirow{2}{*}{ GL } & \multicolumn{6}{|c|}{ Quadrados médios $(\mathrm{cm})$} \\
\hline & & 210DAT & 240DAT & 270DAT & 300DAT & 330DAT & 360DAT \\
\hline Salinidade & 4 & $0,113 \mathrm{~ns}$ & $0,217 n s$ & 0,239 ns & $0,134 n s$ & $0,149 n s$ & $0,098 \mathrm{~ns}$ \\
\hline Bloco & 3 & $0,134 n s$ & $0,164 \mathrm{~ns}$ & $0,978 \mathrm{~ns}$ & $0,161 \mathrm{~ns}$ & $0,169 \mathrm{~ns}$ & $0,363 \mathrm{~ns}$ \\
\hline Resíduo & 12 & 0,239 & 0,121 & 0,091 & 0,105 & 0,111 & 0,138 \\
\hline CV $(\%)$ & & 6,57 & 4,53 & 3,69 & 3,87 & 3,90 & 4,26 \\
\hline Salinidade (dS $\mathrm{m}^{-1}$ ) & & \multicolumn{6}{|c|}{ Média $(\mathrm{cm})$} \\
\hline 0,6 & & 7,675 & 7,875 & 8,450 & 8,625 & 8,800 & 8,900 \\
\hline 1,8 & & 7,400 & 7,575 & 8,375 & 8,550 & 8,700 & 8,900 \\
\hline 3,0 & & 7,300 & 7,625 & 7,975 & 8,225 & 8,300 & 8,600 \\
\hline 4,2 & & 7,300 & 7,425 & 7,900 & 8,225 & 8,525 & 8,650 \\
\hline 5,4 & & 7,575 & 8,000 & 8,275 & 8,400 & 8,500 & 8,600 \\
\hline
\end{tabular}

** significativo a $1 \%$ de probabilidade; $\mathrm{ns}=$ não significativo pelo teste $\mathrm{F}$

de CEa. Em outra oleaginosa, a mamoneira, Cavalcanti et al. (2005) observaram, aos 80 dias após a germinação, pequena redução no diâmetro de caule, com declínio de 0,2 mm (1,45\%) por aumento unitário da CEa.

É possível haver diferenças dos efeitos de salinidade entre espécies de plantas, entre genótipos de uma mesma espécie e entre estádios de desenvolvimento de um mesmo genótipo (Sun et al., 2009; Yao et al., 2010).

Em relação á produção de sementes (Figura 1A), as coletas se iniciaram aos 240 DAT, com média de 17,4 sementes nos cinco tratamentos de salinidade, subindo para 37,1 sementes, aos 270 DAT; na primeira data, foi muito baixo o número de sementes produzidas nos níveis de CEa de 4,2 e 5,4 dS m${ }^{-1}$, sem qualquer explicação possível, considerando-se que as plantas estavam submetidas a esses níveis de salinidade, há 270 dias e que, após essa data, começou a aumentar a produção. Na última coleta, realizada aos 360 DAT (Figura 1E), a produção de sementes foi semelhante entre os tratamentos de salinidade, com exceção das plantas recebendo o nível de maior CEa $\left(5,4 \mathrm{dS} \mathrm{m}^{-1}\right)$, cuja produção foi cerca de $200 \%$ superior à registrada nos outros tratamentos; não estão apresentados dados de regressão polinomial, relacionada à ultima coleta de sementes, por não ter sido possível a obtenção de um ajuste matemático adequado.

Voltando-se a analisar os dados obtidos nas coletas anteriores, o maior número de sementes coletadas aos 240 DAT foi 28,5 e, nas datas seguintes, os valores obtidos foram: $57 \mathrm{em}$ 270 DAT; 118 em 300 DAT e 531 em 330 DAT; nessa última data foi maior a produção de sementes, coincidindo com o pleno período de chuvas.

Pela equação de regressão, obtida aos 330 DAT (Figura 1D), a produção máxima de sementes foi registrada nas plantas de pinhão-manso que receberam água com condutividade elétrica de 2,3 dS m ${ }^{-1}$, com uma produção aproximada de 493 sementes; mas, comparando-se os dados de produção de sementes registrados no nível mais baixo de salinidade $(0,6 \mathrm{dS}$ $\mathrm{m}^{-1}$ ), com os obtidos nos níveis mais altos de condutividade elétrica, constata-se que até $4,0 \mathrm{dS} \mathrm{m}^{-1}$ não houve queda no número de sementes; portanto, a salinidade favoreceu a produção de sementes, até esse nível alto de $\mathrm{CEa}$, podendo ser o pinhão-manso classificado como tolerante à salinidade, em termos de produção de sementes, com base em critérios utilizados por Fageria (1985), aplicados ao arroz, e por Igartua et al. (1995), trabalhando com sorgo.
A.

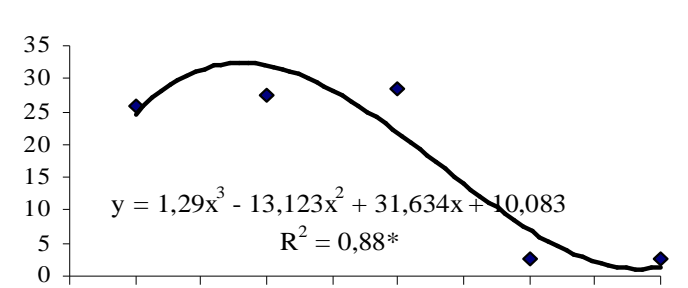

C.
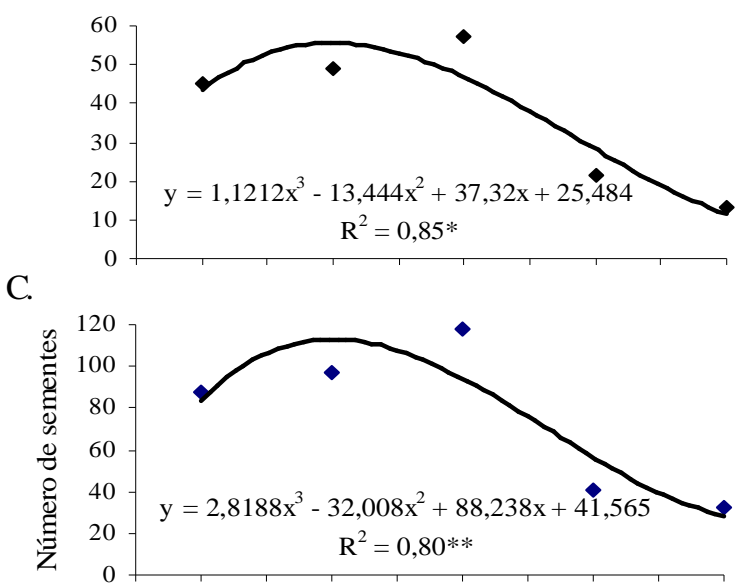

D.

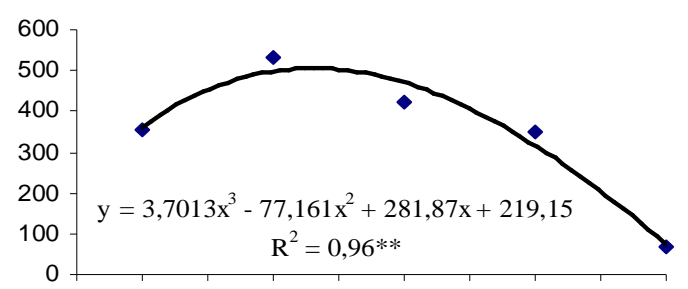

E

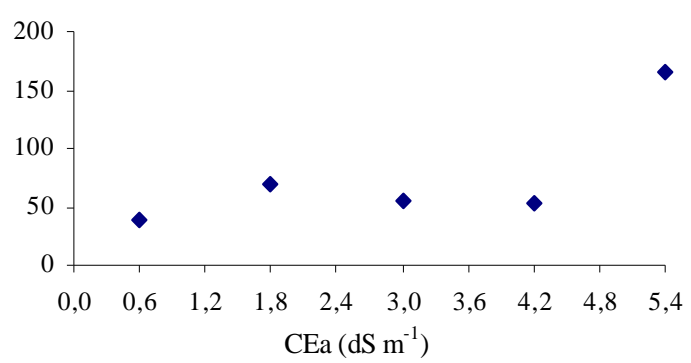

Figura 1. N úmero médio de sementes produzidas pelas plantas, em função dos tratamentos de salinidade da água de irrigação (CEa). A - coleta aos 240 D AT; B- 270 DAT; C300 DAT; D- 330 D AT; E- 360 D AT (D iasapóstransplantio) 
Analisando-se os modelos matemáticos, para número de sementes, obtidos nos vários períodos de análises, nota-se ter aumentado a tolerância à salinidade de 270 até 330 DAT (Figura 1A, 1B, 1C e 1D).

Segundo Harkamal et al. (2006) e Hu et al. (2008), em geral as plantas irrigadas com águas salinas reduzem o crescimento, fato não verificado nesta pesquisa. Trabalhando com mamoneira, Silva (2004) observou redução do número de frutos por cacho, com o incremento da $\mathrm{CEa}$; inclusive, a cultivar BRS Paraguaçu não chegou a frutificar quando irrigada com água de $4,70 \mathrm{dS} \mathrm{m}{ }^{-1}$. Redução de produção pela salinidade também foi constatada por Souza Júnior et al. (2005), em experimento com algodão colorido, tendo observado diminuição de $6,6 \%$ no número de capulho, por incremento unitário da condutividade elétrica da água de irrigação.

\section{ConClusÕES}

1. No período de 210 aos 360 dias após transplante, a altura de planta e o diâmetro caulinar do pinhão-manso não são afetados pela salinidade da água de irrigação, variando de 0,6 a $5,4 \mathrm{dS} \mathrm{m}^{-1}$.

2. O pinhão-manso pode ser classificado como tolerante à salinidade, com produção de sementes favorecida até $4,0 \mathrm{dS} \mathrm{m}^{-1}$.

3. Maior produção de sementes é obtida com água salina de $2,28 \mathrm{dS} \mathrm{m}^{-1}$.

\section{LITERATURA CITADA}

Achten, W. M. J.; Verchot, L.; Franken, Y. J.; Mathijs, E.; Singh, V. P.; Aerts, R.; Muys, B. Jatropha bio-diesel production and use. Biomas and Bioenergy, v.32, p.1063-1084, 2008.

Andréo-Souza, Y.; Pereira, A. L.; Silva, F. F. S.; Riebeiro-Reis, R. C.; Evangelista, M. R. V.; Castro, R. D.; Dantas, B. F. Efeito da salinidade na germinação de sementes e no crescimento inicial de mudas de pinhão-manso. Revista Brasileira de Sementes, v.32, p.83-92, 2010.

Armas, C.; Padilla, F. M.; Pugnaire, F. I.; Jackson, R. B. Hydraulic lift and tolerance to salinity of semiarid species: Consequences for species interactions. Oecologia, v.162, p.11-21, 2010.

Beltrão, N. E. de M. Considerações gerais sobre o pinhãomanso (Jatropha curcas L.) e a necessidade urgente de pesquisas, desenvolvimento e inovações tecnológicas para esta planta nas condições brasileiras. Campina Grande: EMBRAPA. 2006. 4p.

Cavalcanti, M. L. F.; Fernandes, P. D.; Gheyi, H. R.; Barros Júnior, G.; Soares, F. A. L.; Siqueira, E. C. Tolerância da mamoneira BRS 149 à salinidade: Germinação e características de crescimento. Revista Brasileira de Engenharia Agrícola e Ambiental, v.9, p.57-61, 2005.

Correia, K. G.; Fernandes, P. D.; Gheyi, H. R.; Gurgel, M. T.; Rodrigues, L. N. Crescimento do amendoinzeiro irrigado com águas salinas. Revista Brasileira de Engenharia Agrícola e Ambiental, v.9, suplemento, p.81-85, 2005.
Drumond, M. A.; Santos, C. A. F.; Oliveira, V. R.; Martins, J. C.; Anjos, J. B.; Evangelista, M. R. V. Desempenho agronômico de genótipos de pinhão manso no semiárido pernambucano. Ciência Rural, v.40, p.44-47, 2010.

Fageria, N. K. Salt tolerance of rice cultivars. Plant and Soil, v.88, p.237-243, 1985.

Ferreira, P. V. Estatística experimental aplicado à agronomia. 3.ed. Maceió: UFAL. 2000. 604p.

Harkamal, W.; Clyde, W.; Abdul, W.; Pascal, C.; Xinping, C.; Timothy Jr., C. Expression analysis of barley (Hordeum vulgare L.) during salinity stress. Functional \& Integrative Genomics, v.6, p.143-156, 2006.

Hu, Y.; Burucs, Z.; Schmidhalter, U. Effect of foliar fertilization application on the growth and mineral nutrient content of maize seedlings under drought and salinity. Soil Science \& Plant Nutrition, v.54, p.133-141, 2008.

Igartua, E.; Gracia, M. P.; Lasa, J. M. Field responses of grain sorghum to a salinity gradient. Field Crops Research, v.42, p.15-25, 1995.

Jácome, A. G.; Fernandes, P. D.; Gheyi, H. R.; Gonçalves, A. C. A.; Silva, F. F. Avaliação de genótipos de algodoeiro sob níveis de salinidade da água de irrigação. Revista Brasileira de Engenharia Agrícola e Ambiental, v.9, suplemento, p.365-369, 2005.

Medeiros, J. F. Qualidade de água de irrigação e evolução da salinidade nas propriedades assistidas pelo 'GAT' nos estados de RN, PB e CE. Campina Grande: CCT/UFPB, 1992. 173p. Dissertação Mestrado

Nery, A. R.; Rodrigues, L. N.; Silva, M. B. R.; Fernandes, P. D.; Chaves, L. H. G.; Dantas Neto, J.; Gheyi, H. R. Crescimento do pinhão-manso irrigado com águas salinas em ambiente protegido. Revista Brasileira de Engenharia Agrícola e Ambiental, v.13, p.551-558, 2009.

Nóbrega, R. S. Um pensamento crítico sobre classificações climáticas: de Köppen até Strahler. Revista Brasileira de Geografia Física, v.3, p.18-22, 2010.

Pell, M. C.; Finlayson, B. L.; McMahon, T. A. Updated world map of the Köppen-Geiger climate classification. Hydrology and Earth System Sciences, v.11, p.1633-1644, 2007.

Severino, L. S.; Vale, L. S.; Beltrão, N. E. de M. Método para medição da área foliar do pinhão manso In: Congresso da Rede Brasileira de Tecnologia do Biodiesel. 1, 2006, Brasília. Anais... Brasília: IBPS, 2006. p.73-77.

Silva, S. M. S. Germinação, crescimento e desenvolvimento de genótipos de mamoneira irrigados com águas salinas. Campina Grande: UFCG, 2004. 74p. Dissertação Mestrado Souza Júnior, S. P.; Soares, F. A. L.; Siqueira, E. C.; Gheyi, H. R.; Fernandes, P. D.; Beltrão, N. E. de M. Germinação, crescimento e produção do algodoeiro colorido BRS verde sob estresse salino. Revista Brasileira de Engenharia Agrícola e Ambiental, v.09, p.236-241, 2005.

Sun, J.; Dai, S.; Wang, R.; Chen, S.; Zhou, X.; Shen, X.; Zheng, X.; Zhang, Z.; Song, J.; Xu, Y. Calcium mediates root $\mathrm{K}^{+}$ $\mathrm{Na}^{+}$homeostasis in poplar species differing in salt tolerance. Tree Physiology, v.29, p.1175-1186, 2009. 
Toral, O. C.; Iglesias, J. M.; Montes, S. O.; Sotolongo, J. A.; García, S.; Torsti, M. Jatropha curcas L., una especie arbórea con potencial energético en Cuba. Pastos yForrajes, v.31, p.1-1, 2008. Vale, L. S.; Severino, L. S.; Beltrão, N. E. de M. Efeito da salinidade da água sobre o pinhão manso. In: Congresso da Rede Brasileira de Tecnologia do Biodiesel. 1, 2006, Brasília. Anais... Brasília: IBPS. Anais... 2006. p.87-90.
Vengosh, A. Salinization and saline environments. Treatise on Geochemistry, v.9, p.1-35, 2007.

Yao, X.; Horie, T.; Xue, S.; Leung, H. Y.; Katsuhara, M.; Brodsky, D. E.; Schroeder, J. I. Differential sodium and potassium transport selectivities of the rice OsHKT2;1 and OsHKT2;2 transporters in plant cells. Plant Physiology, v.1, p.341-355, 2010. 